Indexaciones: Repositorio de Revistas UCR, DIALNET, Latindex, REDALYC Directorio y recolector de recursos digitales del Ministerio de Cultura de España, Directory of Open Access Journals.

\title{
El México porfiriano y sus relaciones con Centroamérica. Una mirada a la labor diplomática de Enrique C. Creel (1907-1910)
}

\author{
María Esther Montanaro Mena
}

María Esther Montanaro Mena. Bachiller en Historia por la Universidad de Costa Rica y Maestra en Historia por la Universidad Nacional Autónoma de México.

Correo electrónico:

maria esther montanaro@yahoo.com Quiero agradecer ampliamente a la Dra. Mónica Toussaint por su ayuda desinteresada, así como por haberme facilitado material documental del Archivo Histórico de la Secretaría de Relaciones Exteriores y por sugerirme valiosas referencias bibliográficas. 


\section{A manera de introducción}

Tras el cambio de milenio y en pleno inicio del nuevo siglo, México se presta a conmemorar dos hechos fundacionales de su historia, a saber: el bicentenario de la independencia (1810) y el centenario de la Revolución mexicana (1910). A partir de esta particular coyuntura, tal pareciera que el quehacer historiográfico en aquél país, se muestra dispuesto a asumir y comprender ${ }^{1}$ estos dos controvertidos procesos, lo mismo que a sus protagonistas, los cuales durante las últimas décadas se han convertido de manera cada vez más frecuente, en objeto de reinterpretación. Buena parte de los resultados arrojados por las investigaciones recientes, expresan valoraciones más equilibradas y matizadas acerca de dichos procesos y protagonistas. La presente ponencia pretende orientarse en esa misma dirección.

El interés central de este trabajo es el de dar respuesta a algunas preguntas relevantes y vinculadas de manera directa a la política exterior, que fuera dirigida hacia Centroamérica, durante el régimen porfiriano, y más particularmente, a partir del segundo lustro de la primera década del siglo xx. En este sentido, las principales cuestiones que guían esta ponencia son las siguientes: ¿Qué importancia tuvo la región centroamericana para el régimen de Díaz, de modo especial en su etapa final? Y la segunda, ¿qué intereses motivaron a México para pretender "exportar" la pax porfiriana al istmo, más allá de la evidente intención de poner freno a la creciente ambición geoestratégica, comercial y diplomática que sobre esta región mantenía Estados Unidos? Para abordar estas interrogantes, analizaré la labor diplomática realizada por un particular político porfiriano, me refiero a Enrique C. Creel, quien intervino -en calidad de embajador de México en Washington- en el intento por propiciar la paz en la región en 1907, y quien participó también en la instalación de la Corte de Justicia Centroamericana en Cartago, Costa Rica, en 1908.

$1 \quad$ Eugenia Meyer, Programa del "Seminario historia del siglo XX. Sociedad y cultura. Los usos cinemáticas del porfiriato" (México: Facultad de Filosofía y Letras, Universidad Nacional Autónoma de México, agosto 2006), 1.

2 Enrique C. Creel nació el 30 de agosto de 1854 y fue hijo de Paz Cuilty y Rubén Creel, de origen anglosajón y quien además de dedicarse al comercio, desempeñó el cargo de cónsul de los Estados Unidos en Chihuahua. Existen dos trabajos de contenido biográfico sobre Enrique C. Creel; no obstante, de ninguno de ellos podría decirse que es estrictamente una biografía, ésta considero que es una tarea pendiente que contribuiría a comprender mejor la historia del México porfiriano. El primer libro es el de Álvaro de la Helguera y García, Enrique C. Creel. Apuntes biográficos, Madrid, Ambrosio Pérez Asensio, 1910. Y el otro trabajo es del bisnieto del propio Enrique Creel, Alejandro Creel Cobian, Enrique C. Creel. Apuntes para su biografía (México, s.i., 1974); que se trató de una edición para distribución familiar. Además de estos textos, se encontraron otros artículos póstumos, como los que se publicaron en el Boletín de la Sociedad Mexicana de Geografía y Estadística, T. 43, en 1932 ca. 
Antes de pasar a dar respuesta a las interrogantes arriba planteadas, cabe advertir que el régimen porfiriano hasta hace un par de décadas -y esto en gran medida gracias al discurso difundido por la historia oficial- fue considerado de manera maniquea como una etapa oscura y plagada de vicios, que a su vez, fueron los causantes directos de las tremendas desigualdades sociales, económicas y políticas que por entonces, esta nación padecía, y que a su vez, desembocaron en la irrupción de la primera revolución social del siglo xx en América Latina. Es así que, el porfiriato fue "visto" durante más de medio siglo, a través del prisma de los intereses ideológicos y políticos de la Revolución mexicana, que veía en el porfiriato su justificación, lo mismo que su explicación. Así, los gobiernos posrevolucionarios pusieron particular énfasis en las rupturas entre un régimen y el otro, dejando al margen las continuidades, y más aún, las similitudes que ineludiblemente existen entre ambos regímenes.

Así pues, las distorsiones, la satanización y el surgimiento de mitos con respecto a la figura de Porfirio Díaz y del régimen que éste encabezó por poco más de tres décadas, constituyen en la actualidad serios retos para el quehacer historiográfico. En este sentido, se debe decir que, el estudio a detalle del rubro de la diplomacia y de la política exterior porfirianas demandan una atención urgente, tal y como lo ha advertido el historiador británico Paul Garner en su biografía política sobre el "hombre de Oaxaca”. ${ }^{3}$ Lo anterior a razón de que ambos temas pueden arrojar luz para una mejor comprensión, no sólo del presente de la nación mexicana, sino también de su relación con Centroamérica, en tanto que permite establecer un acercamiento al estudio histórico de ese “triángulo fatal” conformado por los Estados Unidos, México y la región centroamericana. ${ }^{4}$

\section{El porfiriato: algunas generalidades}

El régimen instaurado por Porfirio Díaz en 1877, tuvo como principal característica la búsqueda de la estabilidad política y del orden en un país que, desde su proceso de independencia sufrió graves estragos a causa de varias intervenciones extranjeras y de reiteradas guerras civiles. ${ }^{5}$ Es así 3 Paul Garner, Porfirio Díaz. Del héroe al dictador, una biografía política (México: Editorial Planeta, 2003).

$4 \quad$ Al parecer de Cosío Villegas, cualquier estudio de las relaciones de México y Estados Unidos (y viceversa) estaría incompleto, sino se presta la debida atención a la región centroamericana, “el tercer vértice de ese triángulo fatal”. Daniel Cosío Villegas, Historia moderna de México, El Porfiriato, Vida política exterior, Primera parte (México: Editorial Hermes, 1961), XVIII.

5 Resulta sorprendente recordar que, la Nueva España representa el único caso de un virreinato con dos audiciencias que, tras su independencia logró mantenerse unido. Aunque en dos ocasiones corrió el riesgo de 
que, la pax porfiriana fue el resultado de la conformación de un gobierno fuerte y autoritario, que con gran habilidad supo articular y establecer un equilibrio entre las distintas fuerzas políticas y sociales, el cual procuró expresarse también en el ámbito de las relaciones internacionales. Durante su mandato, México experimentó un sorprendente avance en términos económicos, lo que abrió la posibilidad a ciertos grupos de poder para que prosperaran y consolidaran sus capitales, tal fue el caso del clan Terrazas-Creel en el estado de Chihuahua; ${ }^{6}$ grupo social del cual proviene la interesante, polémica y aún poco estudiada figura de Enrique C. Creel, a quien entre otros cargos de importancia, le correspondió ejercer en dos ocasiones el de gobernador del estado de Chihuahua (1904-1907 y 1907-1911) -primero como interino y después por haber ganado la correspondiente elección-. También ocupó el puesto de embajador de México en los Estados Unidos (1907-1908) y el de secretario de Relaciones Exteriores (1910).

Sin duda, la particular vida de Enrique C. Creel devela aspectos interesantes del régimen porfiriano, dado el protagonismo quellegó a tener en medio del acelerado proceso de modernización que experimentó México a finales del siglo XIX e inicios del XX, y de manera particular en el desarrollo de su interesante, multicultural y complejo estado natal, entidad en la que el porfiriato se manifestó de manera sui generis. ${ }^{7}$ Lo anterior a causa del veloz incremento de las inversiones dividirse: en 1823 cuando el Imperio de Iturbide fracasó y, una vez terminada la guerra con Estados Unidos en 1848. México, a diferencia del resto de países latinoamericanos, debió enfrentar de manera muy particular el peligro que históricamente ha representado el hecho de tener como vecino inmediato a Estados Unidos. Josefina Zoraida Vázquez y Lorenzo Meyer, México frente a Estados Unidos. Un ensayo histórico, 1776-2000 (México: Fondo de Cultura Económica, 1989), 9.

6 La incorporación al poderoso clan Terrazas, se dio justo en el año 1880, cuando Enrique Creel se casó con su prima Ángela Terrazas, la quinta hija del coronel Terrazas.

$7 \quad$ Chihuahua es el estado más grande de la República mexicana, a pesar de los desmembramientos que sufrió a raíz de los tratados Guadalupe Hidalgo y la Mesilla. La superficie de esta entidad es de aproximadamente 247.087 kilómetros cuadrados, es decir, el 12.53\% de la totalidad del territorio mexicano. Luis González, Tarahumara: la sierra y el hombre (México: Camino, 1994), 11. La particularidad con la que se manifestó el porfiriato en Chihuahua, tiene que ver con la manera en que la dinámica de desarrollo de las estructuras económicas y de las relaciones de producción en aquella entidad se definieron, principalmente en la década de 1880, cuando la denominada guerra contra los apaches parecía haber llegado a fin. Durante esa época prevaleció como principal premisa, la atracción de inversión extranjera, cuyos principales exponentes estuvieron vinculados al clan Terrazas-Creel. Así, la elite local y los inversionistas extranjeros, pretendieron moldear el perfil de la economía, de la política y de la sociedad, con la pretensión de hacer de la entidad, en pleno inicio de siglo, una de las más modernas de México. No obstante, los sectores medios (tales como los rancheros) muy pronto se inconformaron ante los abusos y exceso de privilegios de la elite y de los inversionistas; en adelante, los grupos sociales afectados visualizaron al enemigo a vencer: el poder monopólico de los Terrazas-Creel, tan afín a los intereses estadounidenses. María Esther Montanaro, Una mirada a los indígenas del porfiriato: Enrique C. Creel y la Ley para el mejoramiento y cultura de la raza tarahumara, de 1906, en el estado de Chihuahua (México: tesis de maestría para optar por el grado de maestra en historia, Facultad de Filosofía y Letras, UNAM, 2008), 222. 
extranjeras en actividades tales como: la ferroviaria, la minera y la industrial; siendo que en cada uno de estos rubros, la participación de capitales estadounidenses fue considerable. Así pues, cabe recordar que Creel mantuvo un vínculo muy estrecho con inversionistas del vecino país, con quienes llegó establecer negocios y en cuyas empresas ocupó cargos relevantes. ${ }^{8}$

La participación de Enrique C. Creel en muchas de estas actividades económicas ${ }^{9}$ se vio ampliamente beneficiada a causa de su relación de parentesco con el general Luis Terrazas, oligarca chihuahuense que destacó por el amplio poderío que llegó a tener en la actividad ganadera, aunque no sólo en ella. ${ }^{10}$ En el ámbito de la política chihuahuense, el desempeño de Terrazas le permitió hacerse de cantidades ingentes de tierras, así como de gozar de magníficos privilegios. Es así que, Creel y Terrazas conformaron una mancuerna política y empresarial, cuyo éxito fue respetado, incluso, por el propio Porfirio Díaz. De esa manera, el presidente oaxaqueño esperaba que Terrazas no regresara más a la política, dados los graves desencuentros que ambos habían tenido décadas atrás. ${ }^{11}$ En efecto, la alianza Terrazas-Creel permitió conjugar el gran sentido empresarial del primero, que incluso excedía las fronteras mexicanas, con la impresionante fortuna del segundo, lo que favoreció ampliamente a dar mayor movilización y diversificación al capital de este grupo familiar. ${ }^{12}$ Es así que, desde la década de 1870 los capitales extranjeros habían encontrado en la elite chihuahuense a un grupo económico local consolidado y que muy

8 Enrique C. Creel desempeñó a lo largo de su vida, gran cantidad de cargos y comisiones, entre los que se encuentran: Presidente de la Compañía del Ferrocarril Mineral de Santa Eulalia, Consejero de la Batopilas Minino Co., Vicepresidente de la Compañía del Ferrocarril Kansas City Mexico y Oriente, Presidente de la Compañía del Ferrocarril de Chihuahua al Pacífico, Presidente de la Compañía Eléctrica y de Ferrocarriles de Chihuahua; Consejero de la Compañía de Petróleo de Chihuahua, entre muchas otros cargos. Francisco Almada, Gobernadores de Chihuahua (México: Imprenta de la H. Cámara de Diputados, 1950), 446-447.

$9 \quad$ El nombre de Creel también figuraba entre los fundadores de numerosas industrias en Chihuahua, a saber: Compañía Industrial Mexicana, fundición de hierro y acero; la Concordia, fábrica de tejidos de lana; la Compañía cervecera de Chihuahua; la Internacional S.A., Casa Empacadora; la Mexicana, la Compañía harinera de Chihuahua; la Fábrica de Guadalupe, gran tenería que contaba con una de la mejor maquinaria. Álvaro de la Helguera y García, Enrique C. Creel. Apuntes biográficos (Madrid: Imprenta de Ambrosio Pérez Asensio, 1910), 46.

10 Cabe señalar que, en Chihuahua, fue la actividad ganadera y no la agrícola, la que le dio sentido al latifundio. Luis Aboites, Breve historia de Chihuahua (México: Fondo de Cultura Económica-El Colegio de México, 1994), 121.

11 En los últimos años de su régimen, Díaz renunció a separar el poder político del económico y a limitar el poder político de las oligarquías regionales en sus estados. En consecuencia, los puestos y los empleos gubernamentales otorgados como premio a la fidelidad política, que en México siempre habían sido determinantes para la supervivencia de las clases medias, cayeron bajo el control exclusivo de esas oligarquías estatales.

Friedrich Katz, De Díaz a Madero (México: Era, 2004), 19-20.

12 Aboites, 128. 
hábilmente aprendió “a convivir con ellos y a sacar ventajas”. ${ }^{13}$

En México, entre 1900 y 1910, las inversiones extranjeras se habían acelerado vertiginosamente, de hecho se triplicaron en relación con la cantidad invertida entre 1876 y 1900. Este crecimiento, sin embargo, trajo consigo consecuencias importantes, entre las que se encuentra una tasa de inflación muy alta, que a su vez, produjo la drástica disminución de los salarios reales de la clase media y la clase obrera industrial; así como también llegó a limitar las oportunidades de inversión de los empresarios de clase media al hacer más difícil la obtención de créditos. El gobierno aumentó la carga soportada por estos dos grupos, al elevar sus impuestos para compensar la reducción en el valor de los impuestos pagados por los inversionistas extranjeros y la oligarquía local. Otra consecuencia del aumento en la inversión extranjera fue el de una mayor vulnerabilidad al ciclo económico de Estados Unidos, la cual se manifestó con crudeza durante la crisis económica de $1907 .{ }^{14}$ Los estados fronterizos -y Chihuahua no fue la excepciónpadecieron, especialmente, los efectos de esta crisis.

Es por ello que a lo largo del segundo lustro de la primera década del siglo XX, el lado negativo de aquellas constantes inversiones foráneas empezaron a hacerse notar. En este contexto local cada vez más complejo, le correspondió a Creel no sólo responder por sus propios intereses económicos, sino también procurar desempeñar como gobernador y embajador en Washington, la tarea encomendada por el gobierno de Díaz: participar en la búsqueda de la paz en la región centroamericana. El que Creel hubiera tenido que atender de manera simultánea ambos cargos, pudo haber influido en la postura asumida por éste con respecto al conflicto centroamericano, ya que es muy probable que le interesaran más los asuntos chihuahuenses que los de Centroamérica. ${ }^{15}$ Por otra parte, es también plausible que no quisiera arriesgarse a mantener discrepancias con sus colegas encargados de la diplomacia estadounidense. Habría que considerar, además, que en México la crisis de 1907 provocó un fuerte descontento al interior de la clase obrera industrial y de las clases medias, el cual tendió a ser canalizado a través de la intensificación de sentimientos nacionalistas. $\mathrm{Al}$ respecto Katz advierte: partir de 1906 éste empezaba a experimentar síntomas de una crisis económica y social profunda, era el inicio de una revuelta social que desembocó en la Revolución mexicana de 1910. Un dato relevante, es el de que esta entidad había experimentado hacia 1903 un auge económico sin precedentes, en buena parte como resultado de la creciente inversión extranjera y por el crecimiento sostenido de la economía chihuahuense, el cual se mantuvo hasta 1906. Montanaro, 123-125.
} 
Todavía es materia de disputa entre los historiadores qué tan hondo era ese nacionalismo y hasta qué punto contribuyó al estallido de la revolución. Esa disputa se centra sobre todo en una manifestación específica del nacionalismo: el sentimiento antiestadounidense. ${ }^{16}$

Tomando en cuenta este ambiente de crispación hacia Estados Unidos, ya por los privilegios percibidos por sus capitales en territorio mexicano, ya por el trato preferencial otorgado a los trabajadores estadounidenses; es posible pensar que el gobierno de Díaz también tomara en consideración este factor -que tenía que ver más con la política interna y con la importancia dada a la opinión pública-, conforme definía su postura diplomática frente al gobierno y a la diplomacia de Estados Unidos, así como también en su intento por definir la forma a través de la cual participaría -junto a la potencia del norte- en la búsqueda de la paz centroamericana. En este sentido, Garner se refiere a cómo las cosas se fueron complicando para el régimen de Díaz, pues,

[...] a medida que la oposición política interna aumentaba en el norte de México en 1909 y 1910, el régimen de Díaz fue incapaz de actuar contra las autoridades estadounidenses que permitían las violaciones a las leyes de neutralidad por parte de los conspiradores y activistas antireeleccionistas en aquel país. Por lo tanto, es posible afirmar que, en la víspera de la revolución, las relaciones entre Estados Unidos y México habían alcanzado su punto más álgido desde 1877. Katz ha afirmado que, para 1910, tanto el gobierno como los intereses comerciales de Estados Unidos eran hostiles al régimen de Díaz, factor que desempeñó un papel importante en su desaparición. ${ }^{17}$

Desde los inicios del régimen porfiriano se le dio continuidad a la política exterior de los gobiernos de Benito Juárez y de Sebastián Lerdo de Tejada, los cuales dieron prioridad al fortalecimiento de las relaciones con Estados Unidos, con el doble propósito de acercarse a Washington, pero también para atraer las inversiones de aquél país. El gobierno de Díaz sabía bien que este

$16 \quad \mathrm{Al}$ respecto el autor menciona que, para entonces, muchos mexicanos tenían muy presente en su memoria, que a causa de la guerra con Estados Unidos en 1847, México había perdido la mitad de su territorio. Katz, 21.

17 Garner, 155-156. 
acercamiento debía hacerse con "pies de plomo". Pero al mismo tiempo, a lo interno de la clase gobernante de la época, existía una clara conciencia acerca de la necesidad, de promover también la presencia y la inversión europea; de ahí el interés de mantener buenas relaciones con: Gran Bretaña, Francia, Alemania y España. Más tarde buscó también establecer vínculos con Japón. Se trataba pues, de una estrategia económica y política, para procurar mantener un contrapeso a la creciente dependencia entre México y la joven potencia estadounidense. ${ }^{18}$

En las postrimerías de su régimen, el general Díaz se vio forzado a volver su mirada con mayor cuidado hacia Centroamérica. Lo anterior a causa de varios móviles: 1.) Dar solución a los históricos problemas limítrofes que México mantenía en su frontera con Guatemala. 2.) Evitar que los países centroamericanos llegaran a unirse bajo el liderazgo del presidente guatemalteco Estrada Cabrera (1898-1920), con el apoyo de Estados Unidos. 3.) Buscar que las reiteradas luchas entre los países centroamericanos se desbordaran y provocaran el estallido de un conflicto bélico mayor, que pudiera poner en riesgo la estabilidad interna mexicana, o peor aún, que justificara la intervención militar de Estados Unidos en la región. 4.) Mantener sobre los países centroamericanos un cierto grado de influencia como potencia mediana, con el objeto de poner algún freno a los crecientes intereses geoestratégicos, que Estados Unidos abiertamente mostraba tener sobre el istmo, más aún después de la firma del tratado canalero con Panamá (1903).

De tal suerte que, la circunstancia crítica centroamericana influyó en la relación que México mantenía con su vecino del norte a inicios del siglo xx. En este sentido, uno de los aspectos que interesa destacar, es cómo a pesar de que el gobierno de México se mostraba cada vez más reticente y preocupado ante la creciente hegemonía de Estados Unidos, éste tuvo que trabajar de manera conjunta con la pontencia, en la búsqueda de un mismo objetivo: la paz en Centroamérica. Evidentemente, cada país lo hizo a partir de enfoques, intereses y motivaciones distintas. ${ }^{19}$

$18 \quad$ Ibid., 157-158.

19 Mónica Toussaint, Guadalupe Rodríguez y Mario Vázquez, Vecindad y diplomacia. Centroamérica en la política exterior mexicana, 1821-1988 (México: Secretaría de Relaciones Exteriores, 2001), 123. Valeria Martínez, Agentes diplomáticos en el conflicto centroamericano, 1906-1907 (México: tesina para optar por el grado de licenciada en historia, Facultad de Filosofía y Letras, UNAM, 2003), 1. 


\section{Política exterior y diplomacia: las relaciones entre México y Centroamérica en las postrimerías del porfiriato}

Tal y como lo ha señalado Garner, la historiografía antiporfirista "ha afirmado que, con su esfuerzo por obtener el reconocimiento internacional y, sobre todo, por asegurar la inversión extranjera que su política económica necesitaba para impulsar el desarrollo, el régimen de Díaz traicionó los intereses de la nación, abriendo los brazos a los rapaces empresarios extranjeros que explotaron los recursos del país.” ${ }^{20}$ A partir de esta premisa se argumentó que, el gobierno porfiriano abusó seriamente de la soberanía política y económica de México. No obstante, la evidencia documental e investigaciones recientes indican otra cosa, dado que la historiografía actual tiende a señalar que, para comprender la política exterior porfirista, ésta debe ser analizada desde la perspectiva del siglo xix; es decir, "a partir del punto de vista de la herencia de las dolorosas experiencias que México había padecido desde su independencia y [...] en relación con los objetivos políticos de todos los gobiernos liberales de México posteriores a 1855.”21

Lo anterior permite comprender, al menos en parte, que los liberales de la reforma y del porfiriato tuvieran que enfrentar con gran cautela la compleja tarea de defender la soberanía mexicana, a la par que impulsaban políticas tendientes a abrir las fronteras nacionales al capital, la inversión y la colonización extranjera. En el caso específico de la relación entre México y Estados Unidos, habría que recordar que, ésta había adquirido desde finales del siglo xix, un carácter fundamentalmente económico. Sin embargo, las estructuras productivas de uno y otro país eran tan desiguales que, entre ambos se originó, desde entonces, un “abismo insalvable”. Así pues, quedó planteado desde entonces un dilema, que aún en la actualidad sigue teniendo vigencia no sólo para México, sino también para los países centroamericanos: “¿cómo desarrollar una economía capitalista fuerte y moderna al lado de Estados Unidos y a la vez preservar una identidad y un proyecto nacionales propios?”22 Aquella preocupación debió de ser una constante para el gobierno de Díaz, más aún después de la crisis cubana de 1898, que derivó en que España perdiera el control de la isla, convirtiéndos prácticamente en un protectorado de los Estados Unidos. ${ }^{23}$

$20 \quad$ Garner, 139.

21 A partir de 1855, la política liberal procuró unir el frágil estado mexicano de entonces y su proyecto de construcción de la nación, con el reconocimiento diplomático y el desarrollo de vínculos de carácter económico con la región noratlántica. Ibid., 140.

22 Vázquez y Meyer, 10 y 12.

23 Para entonces, Estados Unidos había convertido a las Filipinas, Guam y Puerto Rico en sus colonias; teniendo ahora a Cuba como su protectorado, el mar Caribe se había convertido, de hecho, en un lago norteamericano. Gutiérrez, 33. 
A partir de aquél crítico momento, el gobierno de Díaz optó por aumentar sus acercamientos diplomáticos con los representantes europeos, como una vía para hacerse de alianzas que contravinieran el creciente poder estadounidense. Sin embargo, el desafío que planteó México junto con sus socios del viejo continente, no fue lo suficientemente fuerte como para frenar la hegemonía de Estados Unidos, para entonces fuertemente afianzada en América Central y el Caribe. ${ }^{24}$ Ya que desde la última mitad del siglo xIx, ambas regiones experimentaron un auge de lo que algunos autores han denominado como la "economía de los postres"; haciendo así referencia a la producción y exportación de cultivos tropicales tales como café, azúcar y plátano hacia Estados Unidos y Europa. Centroamérica se encontraba pues, integrada a la economía mundial como productora de materias primas y como vía de paso de rutas comerciales; siendo Estados Unidos el principal beneficiario de esa situación..$^{25}$ Aquello no era casual, ya que durante mucho tiempo el gobierno estadounidense procuró impedir la injerencia europea en América Central, principalmente la británica; de igual manera, evitó que México se consolidara como potencia media en la región. ${ }^{26}$

En medio de todo este complejo escenario, se debe prestar atención ahora a las circunstancias que configuraron el conflicto centroamericano entre 1906 y 1907, el cual se puede tomar como la antesala a la organización de la Conferencia de Paz de Washington, de cuyo seno, surgió la idea de crear la Corte de Justicia Centroamericana. Algunas de las principales causas de esta crisis regional fueron: la recurrente incapacidad para alcanzar el viejo propósito de darle forma a una república centroamericana; la creciente desconfianza entre los gobiernos vecinos de la región; el surgimiento de caudillos que provocaron graves problemas internos en los países del istmo; el creciente poder político y económico desplegado por los Estados Unidos en el área. ${ }^{27}$

La reacción del gobierno mexicano frente a estas amenazantes circunstancias fue la de tomar con cautela, cartas en el asunto. Para ello procuró dar impulso a una política exterior que tendiera a mejorar su relación con el presidente Theodore Roosevelt (1901-1909), así como con los presidentes centroamericanos con los cuales tenía puntos en común, tal fue el caso de El Salvador y Nicaragua. De este modo, Díaz esperaba fortalecer su posición ante Estados Unidos y especialmente, frente al gobierno guatemalteco. En esta lucha diplomática emprendida con el

$24 \quad$ Garner, 157.

25 Gutiérrez, 36 y 39.

26 Toussaint, 9.

27 Martínez, 27-28. 
propósito de erigirse en líder regional, el papel desempañado por Enrique C. Creel merece ser estudiado, dado que al hacerlo es factible detectar algunas contradicciones y debilidades de la política exterior y diplomática porfiriana.

\section{La labor diplomática de Enrique C. Creel y la Corte de Cartago}

Enrique C. Creel no fue cualquier político, tampoco cualquier diplomático. ${ }^{28} \mathrm{Al}$ momento de haber sido designado por Díaz como embajador de México en Estados Unidos, había acumulado una considerable experiencia política. ${ }^{29}$ Habría que decir, sin embargo, que Creel era ante todo, un prominente hombre de negocios, que con habilidad y astucia había logrado también incursionar con éxito en el ámbito de la política local y nacional. La siguiente cita, tomada del semanario El Mundo Ilustrado, es una clara muestra del reconocimiento del que gozaba, al menos entre algunos sectores adictos al régimen de Díaz. Ésta pone en evidencia cómo a pesar de sus compromisos como gobernador y embajador, no dejó de atender relevantes asuntos de negocios:

Uno de los colaboradores más conspicuos de la titánica labor del señor

Presidente, para la reorganización de nuestro México, el eminente financiero don Enrique C. Creel, -en estos momentos Embajador de la República ante el gobierno de Washington- con la clarividencia del superhombre, y siendo como

$28 \quad$ Enrique Creel fue regidor y síndico del Ayuntamiento de Chihuahua, fue diputado local durante varias legislaturas y en dos ocasiones fue gobernador de su estado natal. Los cargos de carácter diplomático más importantes que asumió - esto a pesar de que no contaba formación en ese rubro-, fueron: embajador de México en los Estados Unidos y secretario de Relaciones Exteriores. También formó parte de una importante comisión mexicana que, el presidente Porfirio Díaz envió a Estados Unidos y Europa, durante el primer lustro del siglo xx. Dicha comisión tenía por objeto, realizar un estudio acerca de la reforma del sistema monetario del país, el cual dio como resultado el cambio del patrón plata por el de oro, en 1905. Los documentos consultados al respecto, dan cuenta de la habilidad que supo desplegar Creel, en ese tipo de negociaciones de alto nivel. Fue así que el secretario de Hacienda, José Y. Limantaour, pensó en él para que realizara misiones importantes en el vecino país del norte. Fondo José Yves Limantour, Centro de Estudios de Historia de México, Carso. CDLIV, rollo 20, Carta de Creel a Limantour, Nueva York, 4 de enero de 1903; Carta de Limantour a Creel, México, 13 de enero de 1903; Carta de Creel a Limantour, Washington, 30 de enero de 1903, 3-4.

29 El nombramiento como embajador fue recibo favorablemente por la opinión pública chihuahuense. Prueba de ello fue la misiva que Silvestre Terrazas envió a Creel a propósito de su designación, y en la cual le comenta que "el nombramiento de Embajador que el Sr. Presidente de la República, hábil, tratador de hombres tuvo á bien conferirle [...] creemos fundadamente que México tendrá un buen Embajador. Ud. bien sabe que soy muy ageno [sic] á la adulación, y por tanto, las palabras que le dirijo son completamente sinceras.” FEC, CXCI, Carpeta 1/3, Terrazas a Creel, Chihuahua, 28 de diciembre de 1906, L. 79 Silvestre Terrazas pariente lejano del general Luis Terrazas, era un agudo periodista chihuahuense, que muy poco tiempo después de haber firmado esa epístola, y desde la trinchera de El Correo de Chihuahua (del cual era el dueño y director), se convirtió en una de las voces más lúcidas y críticas de los abusos de poder perpetrados por el clan Terrazas-Creel. 
es economista de altos vuelos y de gran prosapia intelectual, estudió cuidadosa y discretamente un proyecto para la organización de una Sociedad Anónima que tuviera por objeto establecer entre nosotros la benéfica institución del Seguro de Vida, imprimiéndola [sic] un carácter genuinamente nacional. ${ }^{30}$

Para entonces, el acaudalado chihuahuense había logrado también el respeto de notables empresarios de Estados Unidos. Su muy correcto manejo del idioma inglés, su amplio conocimiento de la cultura norteamericana, así como la estrecha cercanía que mantenía con el régimen de Díaz, le permitió sentirse a sus anchas en los cargos diplomáticos que desempeñó en los Estados Unidos en representación del gobierno mexicano. ${ }^{31}$

Para el régimen de Díaz, el óptimo desempeño demostrado por Creel en funciones internacionales y nacionales realizadas con anterioridad, pesó en buena medida al momento de ser electo como embajador de México en los Estados Unidos, cargo desde el cual, debió atender los conflictos que se desataron en Centroamérica durante los años de 1906 y 1907. El papel del gobierno mexicano en ese contexto, y que por tanto le fue encomendado a Creel, fue el de intentar contribuir a propiciar la paz en la región, al tiempo que debía manejar con reserva la situación frente al gobierno de Theodore Roosevelt.

Habiéndose instalado Creel en la ciudad de Washington en enero de 1907, el ahora diplomático, recibió muy pronto la oferta para ocupar nuevamente, pero ahora de manera constitucional, el gobierno de Chihuahua. ${ }^{32}$ En un inicio, rechazó la propuesta, alegando no poder “aceptar el cargo por estar desempeñando actualmente en esta capital (Washington D.C.) el puesto de embajador que el señor Díaz inmerecidamente se dignó confiarme. Por esa causa y además porque no me considero capaz.” ${ }^{33}$ Sin embargo, pronto cambió de postura y terminó aceptando la candidatura, la cual fue ampliamente elogiada por la prensa oficialista, en especial

$30 \quad$ El Mundo Ilustrado Semanario, “Notable Institución Financiera primera en su género”, 1 de enero 1907. 31 Es importante considerar la ascendencia paterna de Creel, dado que su padre, Rubén Creel, era estadounidense, del estado de Kentucky. Este vínculo, muy probablemente, lo motivó a interesarse por conocer a profundidad la cultura de su padre, de la cual llegó a ser fiel admirador.

32 Hay que recordar que, en la primera ocasión que Creel ocupó la gubernatura de Chihuahua, lo hizo en sustitución de su suegro Luis Terrazas, quien recientemente se había reconciliado con el presidente Díaz. Este arreglo derivó de un pacto que se concretó en 1903, cuando Díaz aseguró estar de acuerdo con que Terrazas sustituyera a Miguel Ahumada, quien durante poco más de una década, había estado a cargo del ejecutivo de aquella entidad. Montanaro, 110.

33 Martínez, 74. 
la de Chihuahua. Aunque la posibilidad de que Creel continuara en el cargo de gobernador, provocó inconformidad en algunos sectores sociales de su estado. ${ }^{34}$

Pues hacia 1907, la elite chihuahuense era objeto de severas críticas. El efecto de la crisis económica de ese año contribuyó a incrementar el descontento social, que se manifestó con fuerza contra el ambiente de crecientes privilegios, nepotismo, corrupción y abusos por parte la poderosísima elite, que tenía en Enrique Creel a uno de sus más importantes representantes. Ante este panorama no es de extrañar que el embajador Creel, hombre profundamente pragmático, prefiriera atender los urgentes asuntos locales que involucrarse de lleno en los centroamericanos. ${ }^{35}$ Al respecto Martínez señala que:

En relación con los asuntos centroamericanos, Creel tendía a manifestar su acuerdo con el Departamento de Estado. Esto se demuestra en sus escritos a Mariscal a favor de los puntos de vista de [Elihu] Root cuando éste propuso delegados de uno y otro para recorrer Centroamérica. Creel temía desilusionar a Root. Igualmente, le pareció una buena idea viajar con [William] Buchanan a Costa Rica en un buque de guerra norteamericano para inaugurar allá la Corte de Justicia Centroamericana, otra vez acatando las propuestas del secretario de Estado. ${ }^{36}$

Pero a pesar de las circunstancias arriba mencionadas, Creel seguía gozando de prestigio y credibilidad en los círculos porfirianos. Es por ello que para el gobierno de Díaz resultaba de

34 La prensa chihuahuense deja ver que, si bien es cierto la primera gestión de Creel como gobernador interino contó con un amplio reconocimiento de la opinión pública, las cosas dieron un giro notable durante la campaña que precedió a su elección como gobernador constitucional. Para empezar, desde el inicio de su candidatura recibió fuertes críticas. Una de ellas fue el cuestionamiento de que, por ser hijo de extranjero la fracción II de la Ley de Extranjería de mayo de 1886, le impedía contender por el gobierno del estado. Los principales ataques fueron difundidos en el periódico El Correo de Chihuahua. Toda esta polémica desató la represión del gobierno local contra los críticos de la candidatura de Creel. Para este tema se recomienda la consulta de Silvestre Terrazas, Pláticas de derecho. La cuestión palpitante: varios artículos que, bajo los títulos citados fueron publicados en El Correo de Chihuahua para dilucidar la cuestión "Mexicano por nacimiento", Chihuahua, s.p.i., 1909.

35 Martínez documenta muy puntualmente en su trabajo, lo recurrentes y prolongados que fueron los viajes realizados por Creel, mientras fue embajador. Quien le sustituyó durante esos lapsos fue José Francisco Godoy, a quien quedaba autorizado para que despachara y firmara la correspondencia oficial. Godoy era el encargado de los negocios en la embajada mexicana desde antes que Creel asumiera el cargo. Además, fue representante de México en las conferencias de Washington y, aunque ocupó un cargo modesto, "fue un buen secretario, una persona eficaz, y supo mantener la relación oficial e informar al ministro de Relaciones Exteriores de su país.” Martínez, 5 y 75. 36 Ibid., 88-89. 
utilidad, que figurara como representante de la diplomacia mexicana en Washington; ${ }^{37}$ prueba de ello es que, en mayo de 1910, fue designado por Díaz como titular de la secretaría de Relaciones Exteriores, a causa de la muerte, en 1909, del titular de esa cartera, Ignacio Mariscal. Al respecto hubo reacciones muy severas en relación con el nuevo nombramiento de Creel en el servicio exterior; un ejemplo de ello fue la postura que Luis Cabrera asumió al respecto. ${ }^{38}$ La siguiente cita, resulta elocuente:

Hoy, flota aún a media asta el pabellón enlutado por la muerte del ministro de Relaciones, y hay los periódicos semi oficiales, el que se publica en español y el que se escribe en inglés, lanzan a diario sus notas o reportazgos sobre los rumores de venida del Sr. Creel como ministro de Relaciones. [...] En el fondo "El Imparcial” desea la venida del Sr. Creel, por razones de partido. El "Mexican Herald” por cuestión de raza. ${ }^{39}$

Con respecto a la labor mediadora conjunta de diplomáticos mexicanos y estadounidenses, se podría decir que, ésta logró alcanzar un efecto más eficaz que los intentos previos realizados por los propios países centroamericanos. Cuando, en febrero de 1907, las tropas nicaragüenses invadieron Honduras, Creel debió participar de manera directa en el asunto. A razón de lo anterior, 37 Porfirio Parra era un reconocido médico e intelectual chihuahuense, amigo cercano de Enrique Creel. Fue además, discípulo de Gabino Barreda y uno de los más comprometidos difusores del positivismo comteano en el México porfiriano. Al igual que Creel, Parra mantuvo un vínculo estrecho con el grupo denominado científicos. Durante buena parte de su vida radicó en la ciudad de México, desde donde estableció comunicación estrecha con Creel. Montanaro, 193. La siguiente cita, deja ver algunas de las ideas que en torno a la figura de Creel existían entre los adeptos al régimen. "Ya sé que en estos momentos trascendentales y decisivos de nuestra historia, en que México, conquistadas la paz, y la prosperidad interiores, comienza á adquirir, no sólo prestigio sino ascendiente en el exterior, al menos en el mundo hispano-americano, un Embajador como tú, cerca del gobierno de la nación más poderosa del continente, y de una de las naciones más poderosas del mundo, no puede menos que encauzar nuestras futuras y legítimas aspiraciones internacionales, y conquistar el puesto que le toca en el concierto de repúblicas que pueblan el mundo de Colón.” Fondo Enrique Creel (en adelante FEC), Centro de Estudios de Historia de México, Carso, CXCI, Carpeta 1/3, L. 80, Parra a Creel, México, 25 de mayo de 1907.

38 Luis Cabrera consideraba que existían dos razones para considerar la designación de Creel como algo contrario “a las tendencias verdaderamente nacionales”. En primer lugar, menciona el vínculo tan estrecho que Creel mantenía con el grupo llamado grupo de los científicos. Y en segundo lugar, porque: "El Sr. Creel por su nombre y por su sangre y por educación y por sus tendencias, es norteamericano. La misma vida política del Sr. Creel es una prueba de ello. Su nombramiento como embajador en Estados Unidos obedeció a sus afinidades con los norteamericanos; su injerencia en la política centro-americana [sic] no ha hecho más que confirmar la idea de que de todos los políticos que viven en México, es el que piensa más de acuerdo con las tendencias norteamericanas.” Agrega Cabrera que a su vez existían no “interesados a favor del nombramiento del Sr. Creel”, uno era el grupo científico que se encontraba representado por El Imparcial, y el otro estaba representado por el Mexican Herald. Luis Cabrera, Obras completas. Obra política, México, Oasis, 1975, t. 3, pp. 156-158. 
el secretario de Estado Elihu Root le solicitó que México cooperara junto a Estados Unidos, en la búsqueda por alcanzar las garantías de paz que Roosevelt había planteado. ${ }^{40}$ La postura de Creel al respecto, era que la embajada mexicana aconsejara a los países de la región, para que solucionaran por la vía pacífica sus diferencias, dejando a los respectivos gobiernos escoger a un árbitro que ayudara a solucionar la crisis. Creel propuso además "un procedimiento que consistía en la retirada de las fuerzas que los países beligerantes tenían en la frontera entre Nicaragua y Honduras”, misma que debía realizarse de manera simultánea. ${ }^{41}$

Más tarde Creel pidió una licencia para ausentarse varios meses. Regresó a Washington poco antes de que iniciara la Conferencia de Paz. Con su participación, Creel contribuyó a lograr el consenso necesario entre México y los Estados Unidos; para el chihuahuense era preferible adaptarse a los lineamientos de la potencia y dejar de lado las demandas de la secretaría de Relaciones Exteriores. Es por ello que al final del día, el gobierno de Díaz se arriesgó al colocar a Creel en ese importante cargo diplomático y al aceptar participar, junto a Estados Unidos, en la mediación de los conflictos centroamericanos, ya que de esta manera legitimó la hegemonía de la potencia en el área. Es así que, al régimen no le quedó más que sacar provecho de su modesto rol como mediador, en la medida en que era conciente de cuántas cosas estaban en riesgo. ${ }^{42}$ Más que eso no pudo lograr el gobierno de Díaz, pues para colmo, Creel tampoco quiso poner más de su parte, en el intento por darle a la diplomacia mexicana un mayor protagonismo y frenar la injerencia estadounidense.

\section{La Conferencia de Washington y la Corte de Justicia Centroamericana (1908-1918)}

La Conferencia de Paz Centroamericana se celebró en Washington del 14 de noviembre al 20 de diciembre de 1907. La reunión fue convocada por los Estados Unidos y México. Previamente, habían sido realizadas consultas ante cada uno de los gobiernos del istmo, los cuales dieron su aprobación a esta iniciativa. El 17 de septiembre de 1907 había sido firmado, en la capital estadounidense, un protocolo que disponía que México y Estados Unidos extendieran la invitación para esta conferencia, a la par que los países signatarios eran obligados a llevar a cabo un armisticio. ${ }^{43} \mathrm{Al}$ respecto, Martínez señala que durante las Conferencias de Paz "la voz 40 Jürgen Buchenau, In the Shadow of the Giant the Making of Mexico's Central America Policy, 18761930 (Tuscaloosa, Alabama: University of Alabama, 1996), 49.

41 Martínez, 73.

42 Buchenau, 49-50.

43 Martínez, 25. 
de bienvenida la llevó el delegado de los Estados Unidos, William Buchanan, en tanto que Creel [...] se limitó a hacer y mantener contactos con los delegados y a informar a [Ignacio] Mariscal del proceso en marcha; demás, estaba conciente de que el gobierno norteamericano tenía la ventaja en la conferencia." ${ }^{44}$

En efecto, tal pareciera que con la participación de Creel en estas conferencias se buscaba poner de manifiesto la buena voluntad, que tenía el gobierno mexicano para que los conflictos centroamericanos se resolvieran. El embajador mexicano se ocupó así por recopilar opiniones de los delegados centroamericanos que participaron en los encuentros; también de mantener muy bien informado al secretario Mariscal, especialmente, acerca del inquietante tema de la posible unión centroamericana. Además, dejó constancia de los elogios otorgados por los delegados en las conferencias a "la obra patriótica del general Díaz." ${ }^{45}$ Este último aspecto, es importante considerarlo dado que, el régimen porfiriano -entre otras cuestiones-, perseguía con aquella mediación, hacer gala de los logros materiales y de la estabilidad alcanzada, a lo largo de casi tres décadas de gobierno; tales logros permitían en parte al gobierno mexicano, dedicar tiempo y esfuerzos en la búsqueda de la paz en el istmo. Al respecto, Creel comentaba que:

Tengo la honra de informar a usted que las delegaciones a la conferencia de paz centroamericana dieron su banquete de despedida el día 21 del actual, al que concurrieron el vice-presidente de la cámara de diputados, el secretario de Estado y varios senadores y otras personas de alta representación en la política Mr. Fairbanks, Mr. Canon, Mr. Root y Mr. Carneglez, por una parte, y por Dr. Anderson, presidente de la conferencia; por la otra. [...] En todos los brindis se hizo alusión honrosa a México, y al señor general Díaz, y creí de mi deber contestar en frases de cortesía. ${ }^{46}$

De igual manera, Creel envió al secretario Mariscal los tratados y protocolos que habían sido aprobados durante la Conferencia de Paz Centroamericana, a saber: Convención para el establecimiento de una Corte de Justicia, Tratado General de Paz y Amistad; Convención de Comunicación, Convención de Extradición, Convención para el establecimiento de un Instituto Pedagógico Centroamericano, Convención de una Oficina Internacional Centroamericana,

$44 \quad$ Ibid., 26.

$45 \quad$ Martínez, 77.

46 Creel a Mariscal, Washington, 23 de diciembre de 1907, AHSREM, L-E-1395, f. 7. 
Convención sobre futuras Conferencias Centroamericanas, Convención adicional al Tratado General, Protocolo adicional para el establecimiento de una Corte de Justicia Centroamericana. ${ }^{47}$

La idea de que existiera la Corte de Justicia Centroamericana fue concebida por las delegaciones salvadoreña y costarricense. ${ }^{48}$ Su creación se dio mediante una convención suscrita el 20 de diciembre de 1907 por Costa Rica, El Salvador, Guatemala, Honduras y Nicaragua, y fue aprobada por todos los países signatarios, con una vigencia de diez años. Sin embargo, por diversas discrepancias no se logró renovar la convención, así pues, ésta caducó y la Corte de Cartago quedó jurídicamente sin valor.

Sin duda, esta Corte de Justicia Centroamericana tuvo un carácter innovador, dada la amplitud de su jurisdicción. Inspirada en ideas muy difundidas internacionalmente desde finales del siglo XIx, a través de las cuales se pretendía fortalecer la paz, a través del arbitraje obligatorio de los conflictos entre países. En este sentido, la creación de la Corte significó un avance sustancial a los logrados hasta aquél momento como resultado de las dos Conferencias de Paz de la Haya, realizadas en 1899 y 1907, respectivamente. La principal innovación pues, se manifestó en la creación de un tribunal de arbitraje de carácter permanente. A este tribunal podrían ser sometidas todas las diferencias, sin que fuese necesario un acuerdo adicional por parte de los países firmantes. En vista de la amplitud de las capacidades otorgadas a esta instancia, algunos especialistas han señalado que hasta hace poco "ningún tribunal internacional anterior o posterior había tenido tantas facultades”. ${ }^{49}$ Así pues, esta institución podía ocuparse de controversias jurídicas y políticas entre países. Podía también atender demandas planteadas por individuos de un Estado contra el gobierno de otro; esta potestad resultó ser otro elemento innovador, aunque en la práctica, la mayoría de estas exigencias no llegaron a ser tramitadas por completo.

Finalmente, se debe decir que, no obstante que a la Corte de Justicia Centroamericana le han sido atribuidos todos estos rasgos innovadores, esta institución tuvo una vida efímera y terminó por fracasar en su intento por consolidar la paz y estabilidad en la región..$^{50}$ Este temprano fracaso se encuentra relacionado a que las prioridades de la política exterior de los 47 Creel a Mariscal, Washington, 28 de diciembre de 1907, L-E- 1395, f. 22-23.

48 Archivo Nacional de Costa Rica, Guía del Fondo Documental. Corte de Justicia Centroamericana, 19081918 (Madrid: Departamento Archivo Histórico, Fundación Histórica Tavera, Archivo Nacional, 2000$), 9$.

49 Ibid., 7.

50 Toussaint, 12. 
Estados Unidos terminaron por imponerse a los planteamientos de este tribunal internacional. Es así que, cabría señalar que, en efecto:

La Corte surgió en 1907 como un ejemplo, entre otros, de una de las modalidades en apariencia más benignas [...] de intervención de la potencia del Norte en Centroamérica: la de asumir la función de pacificador o mediador de una región cuya vulnerable y conflictiva vida política no sólo facilitaba, sino que incluso justificaba esa permanente intervención. [Es así que] esta política de clientelismo y de limitación de facto de la soberanía de los gobiernos centroamericanos tenía necesariamente que chocar con la institución concebida para regular y fortalecer la vida política de las naciones centroamericanas. ${ }^{51}$

El régimen porfiriano consideraba que, a través de su papel mediador en el conflicto centroamericano y como promotor de instituciones que velaran por ese propósito, podría mostrar al mundo, que México no sólo había alcanzado un progreso económico y material sin precedentes; sino que era capaz de influir en el contexto latinoamericano, de manera particular en el istmo. Existía "la convicción de que la mexicana era una de las naciones señeras de América Latina, una suerte de hermana mayor vencedora de la invasión europea que, además, se mantenía firme frente al embate de los anglosajones por el norte mientras lograba el progreso."52 De ahí que el gobierno de Díaz creyera estar en condiciones para ayudar a las naciones hermanas. ${ }^{53}$ De ese modo México trataba de sacar también partido de la situación.

\section{A manera de epílogo}

Desde los orígenes mismos del surgimiento de México como Estado soberano, la relación con su vecino del norte fue motivo de preocupación y tensión. Es por ello que, a lo largo de su historia independiente y hasta nuestros días, este tema ha ocupado un lugar altamente privilegiado en la agenda de los gobiernos mexicanos. El régimen porfiriano, evidentemente, no fue la excepción. Y esa preocupación constante, por añadidura, signó las relaciones que México mantuvo y pretendió establecer con los países centroamericanos.

51 Archivo Nacional de Costa Rica, 9.

52 Gutiérrez, 60.

53 El fracaso del imperio de Maximiliano fue considerado como “la segunda independencia” de México. Justamente, Porfirio Díaz fue uno de los principales héroes, a raíz de su participación en la toma de Puebla el día 2 de abril de 1867, en esta batalla fueron prácticamente vencidos los franceses. Durante el porfiriato, ésta fue la segunda conmemoración más importante, después de la independencia. Ibid., 59. 
Las relaciones diplomáticas entre México y Centroamérica iniciaron en la tercera década del siglo xIx, después de culminados los respectivos procesos independencia de España. A partir de ese momento, cada uno de estos países siguió un rumbo accidentado, complejo e irremediablemente vinculado a sus propios vaivenes políticos internos y al contexto internacional. ${ }^{54}$

Centroamérica ha sido una región en la cual, históricamente han confluido muy diversos, importantes y conflictivos intereses. Esto pareciera explicar en parte, el que las relaciones internacionales de estos países estén marcadas por la necesidad del establecimiento de alianzas que sirvan de contrapeso para evitar el predominio de alguno de los países. ${ }^{55}$ En este sentido, la política exterior y la diplomacia porfiriana trataron de sacar provecho de este rasgo tan propio de la región. Para ello se alió, a inicios del siglo xx a Nicaragua y a El Salvador, países que por principio de cuentas, se oponían a la pretensión que tenía Guatemala para dominar en el área, lo que resultaba ser favorable para los intereses del Estado mexicano.

Pero sin duda, el factor que de manera más decisiva marcó el devenir histórico de México, Centroamérica y el Caribe, es su proximidad con los Estados Unidos. ${ }^{56}$ Esta potencia, desde finales del siglo xIx, no ha dejado de velar por sus intereses e inversiones en esta extensa región, a la que considerada como parte de su esfera natural de influencia. El régimen de Porfirio Díaz vio con temor el aumento del predominio hegemónico de la joven potencia, así como las pretensiones de Guatemala, ${ }^{57}$ que procuró apoyarse en ella. Es por ello que, México procuró sacar provecho de la estabilidad y control interno que había logrado alcanzar a lo largo de su prolongado mandato. Lo anterior le permitió desarrollar una política exterior activa en Centroamérica y en el Caribe, con el objeto de hacer de México un actor en el escenario internacional. ${ }^{58}$ Sin embargo, en los hechos tal política exterior y diplomática tuvo serias limitantes, las cuales generaron secuelas tremendas que, sumadas a las crisis que se produjeron en ámbito político, económico, social y cultural, contribuyeron al posterior estallido revolucionario de 1910.

En el caso concreto de los conflictos centroamericanos de 1906 y 1907 fue muy claro, que el poderío de los Estados Unidos no estaba dispuesto a permitir que la diplomacia mexicana brillara más de lo que le convenía. De modo que, el que Díaz hubiera escogido a Enrique C. Creel

$54 \quad$ Toussaint, 9.

55 Ibid.

56 Vázquez y Meyer, 10.

57 Buchenau, 49.

58 Jürgen Buchenau, "Mexico como potencia mediana: una perspectiva histórica”, Secuencia Revista de historia y ciencias sociales (México) 41 (mayo-agosto, nueva época): 79. 
como embajador de México en aquél país, terminó allanándole el camino a la potencia, dado que éste se caracterizó por ser sumamente condescendiente a los intereses estadounidenses.

A lo anterior habría que agregar que, para inicios del siglo xx, la situación de México era realmente compleja, pues aunque en apariencia había estabilidad interna, esa imagen no era más que un frágil cascarón con el que se pretendía ocultar la realidad: que se estaba gestando un torbellino social inconmensurable, particularmente en Chihuahua, el estado natal de Creel. Es así que las dificultades que México debió enfrentar fueron tanto de índole interna como externa.

La labor diplomática emprendida durante el régimen de Porfirio Díaz respecto a Centroamérica, estuvo signada por tres grandes temores, aunque no eran los únicos: que Guatemala continuara promoviendo la unión centroamericana, que Estados Unidos continuara ampliando sus inversiones y poder político dentro de las fronteras mexicanas y que, la potencia del norte incrementara su poder geopolítico sobre las naciones del istmo. A lo que habría que agregar un cuarto aspecto que le interesó y preocupó ampliamente al régimen: su imagen internacional, justamente en el contexto previo a las celebraciones del centenario de la Independencia, en las cuales serían también festejados los logros alcanzados durante el porfiriato en materia diplomática. ${ }^{59}$

Para 1910, las relaciones entre Estados Unidos y México se habían vuelto cada vez más conflictivas; ejemplo de ello fue la reunión de los presidentes Díaz y Taft en la frontera entre ambos países en octubre de 1909 y en la cual, Enrique C. Creel fungió como traductor. Con aquella cita se pretendió dar una muestra de la buena salud de la que gozaban las relaciones diplomáticas; pero en el fondo existían graves tensiones. ${ }^{60}$

A razón de haber sido electo gobernador constitucional de Chihuahua, Creel solicitó en septiembre de 1908 ser sustituido del cargo de embajador en Washington; es así que fue reemplazado por Francisco León de la Barra. ${ }^{61}$ Pero no deja de sorprender que, para finales de $59 \quad$ Entre los monumentos que fueron construidos para conmemorar este centenario, se encuentra la inauguración de la estatua de George Washington, con la cual se pretendieron celebrar las relaciones entre México y Estados Unidos. Garner, 161.

60 Ibid., 156.

61 "En tu última carta expresaste el deseo de saber mi opinión é impresiones acerca de tu renuncia al puesto de Embajador. Por la prensa me enteré del documento en que presentaste tal renuncia, y no pude menos que admirar el profundo patriotismo, el vivo sentido del deber y el consumado tacto que se traslucían en tan interesante documento [...]. En cuanto al hecho en sí mismo te diré que, si bien lamento que te hayas separado de un puesto en que prestaste tan grandes servicios, y que desempeñabas con brillo sin igual, celebro que lo hayas hecho así, en primer lugar porque eran tus deseos, y en segundo porque podrás ahora consagrar tu excepcional y fecunda actividad á mejorar los destinos de Chihuahua.” FEC, Parra a Creel, México, 19 de noviembre de 1908, 
1909 le fuese encomendada otra misión diplomática importante, la de ser embajador especial en Washington para discutir el conflicto suscitado entre Nicaragua y los Estados Unidos, en virtud de una revuelta contra el presidente nicaragüense, José Santos Zelaya.

En esta ponencia he procurado hacer una reflexión, la primera que llevo al papel en torno a los vínculos que unieron a la región centroamericana con México durante el ocaso del régimen porfiriano. Para ello, fue inevitable considerar ese otro vértice del "triángulo fatal", es decir, Estados Unidos; país que al final de cuentas, marcó y sigue marcando el devenir de nuestra región. El pasado referéndum en torno a la aprobación o no del TLC en Costa Rica, fue un ejemplo clarísimo y pasmoso acerca de la desmesurada injerencia que la potencia del norte -apoyada en el servilismo de las oligarquías locales- sigue teniendo en Centroamérica. De ahí que considere que, más allá de los alcances y las limitaciones de este trabajo, lo relevante es en todo caso, que éste sirva como pretexto para seguir reflexionando acerca de cuáles son las posibilidades para que nuestros países, puedan en un futuro cercano, hacer valer su derecho a regir soberanamente el destino de sus naciones.

L. 90. 